\title{
Swept Area Variation with Depth and its Influence on Abundance Indices of Groundfish from Trawl Surveys
}

\author{
Olav Rune God $\varnothing$ \\ Institute oi Marine Research, P. O. Box 1870 \\ 5024 Bergen, Norway \\ and \\ Arill Engås \\ Institute of Fisheries Technology Research \\ P. O. Box 1964, 5024 Bergen, Norway
}

\begin{abstract}
Norwegian stratified-random bottom trawl surveys are carried out under the assumption that a constant area is swept by the trawl during a standard haul to generate abundance indices. Results from measurements of trawl geometry during a trawl survey in the Svalbard area, showed that there was a considerable depth dependency, and to a lesser extent, area/bottom stratum dependency of wingspread. Assuming that the swept area was linearly related to the wingspread, it was found that the currently applied method relatively underestimates the younger ages of cod (1-3 years) in the Svalbard area. The use of instruments for monitoring trawl geometry during all tows is one way to diminish variability in bottom trawl survey indices.
\end{abstract}

\section{Introduction}

Stratified-random bottom trawl surveys are often carried out under the assumption that a constant area is swept by the trawl in a standard haul (Forest and Minet, 1981; Halliday, 1986). Swept area abundance indices for Northeast Arctic cod have annually been calculated separately for the Barents Sea and the Svalbard area (Fig. 1) since 1981 (Hylen et al., 1986; Hylen et al., MS 1988a, b). The two sets of indices have been combined and used in management of the stock (Hylen and Nakken, MS 1985).

The survey areas of the Barents Sea vary little in deptr: $250 \pm 50 \mathrm{~m}$ (Jacobsen, MS 1986). The Svalbard area, however, is characterized by depth variation from about 20 to $600 \mathrm{~m}$. These were the depth limits of the survey and the survey stratification follows the depth contours. It is known that the area swept by a trawl increases with depth towards a limiting value as a result of increasing warp length (Carrothers, 1981). According to previous Svalbard survey results, it is also known that a depth displacement with age occurs for many of the groundfish species (God $\varnothing$ and Nedreaas, MS 1986). Thus without adjustments for the effect of depth on area swept, the estimated indices of the different age groups may be significantly biased. It has been suggested that during survey operations, varying sweep wire lengths at different depths would compensate for difference in swept area with depth (Wileman, 1984; Jonsson et al., MS 1986).
In 1985, trawl geometry (wingspread and height) was observed during normal trawling operations in the Svalbard survey. In this paper the standard bottom trawl indices of cod abundance are examined in light of changes in trawl geometry and its relation to bottom

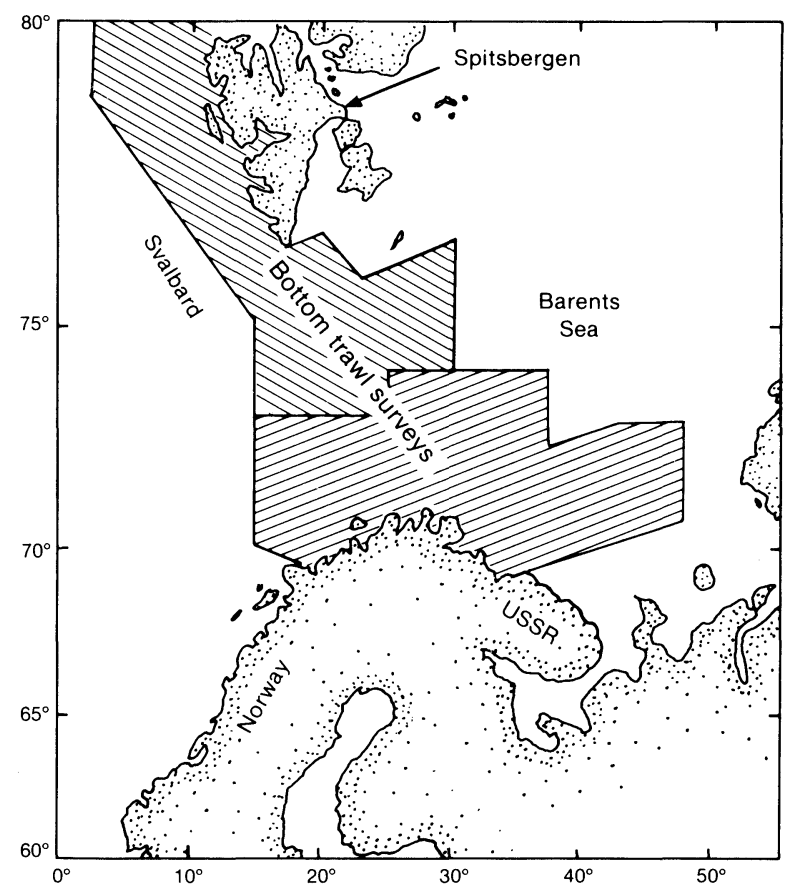

Fig. 1. The Svalbard and Barents Sea survey areas. 
depth. Irregularity in trawl geometry and performance as sources of variability in trawl surveys are discussed.

\section{Materials and Methods}

\section{The survey}

The data were collected during the 1985 standard Svalbard bottom trawl survey (God $\varnothing$ and Nedreaas, MS 1986). During this stratified-random trawl survey, a total of 202 trawl stations were occupied. Of these, 94 were by the research vessel (R/V) Eldjarn, $(60.3 \mathrm{~m}$ LOA3,400 horsepower) and 108 by the vessel $M / T$ Raiti, (46.7 m LOA-1,200 horsepower). Observations of the wingspread (WS) and trawl height (TH) were made on 131 hauls (Table 1 ).

\section{Fishing gear and instrumentation}

The standard bottom sampling trawl of the survey was a Campelen 1800 shrimp trawl (Fig. 2). Eldjarn was

TABLE 1. Number of measurements of wingspread (WS) and trawl height $(\mathrm{TH})$ on the R/V Eldjarn and $\mathrm{M} / \mathrm{T}$ Raiti.

\begin{tabular}{lccc}
\hline \hline Vessel & WS & TH & WS+TH \\
\hline Eldjarn & 40 & 86 & 30 \\
Raiti & 34 & 34 & 34 \\
\hline
\end{tabular}

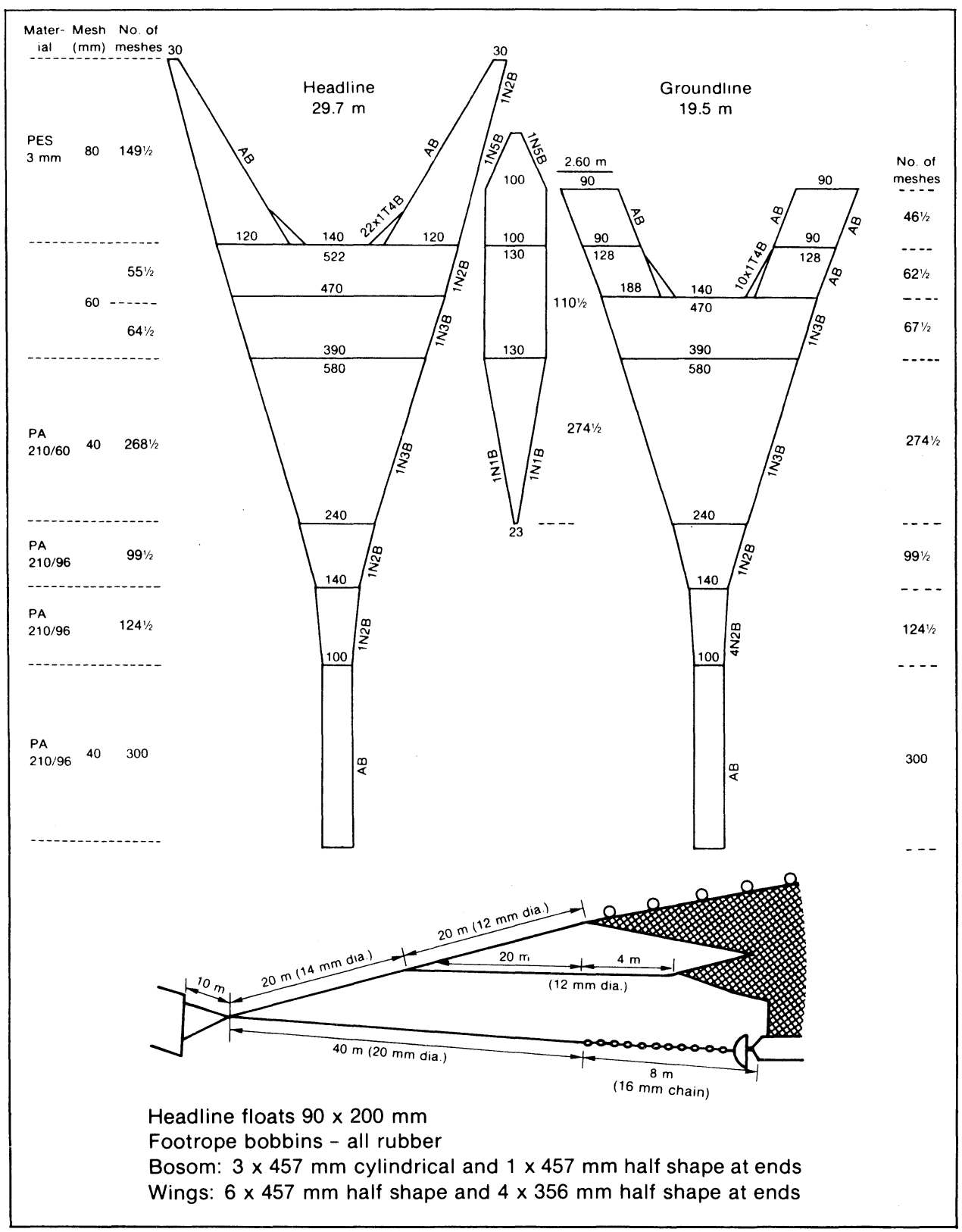

Fig. 2. Details of Campelen 1800 shrimp trawl used as the standard trawl in the survey. 
equipped with $6 \mathrm{~m}^{2}$ Waco-doors $(3.00 \mathrm{~m} \times 2.04 \mathrm{~m}), 1,500$ $\mathrm{kg}$, while Raiti used $6.4 \mathrm{~m}^{2}$ Vee-doors $(3.65 \mathrm{~m} \times 2.02 \mathrm{~m})$, $1,750 \mathrm{~kg}$. Warp lengths usually $2-3$ times the bottom depth were used, ratio decreasing with increasing depth. All observations of trawl geometry were done with SCANMAR acoustic instrumentation. A height sensor was mounted on the trawl headline while sensors for measuring distance were hung on the sweep wires $20 \mathrm{~cm}$ in front of the headline wing tips. Stable readings of the TH and WS were recorded from the SCANMAR digital display every $5 \mathrm{~min}$. during the standard hauls ( $1 \mathrm{hr}$ at 3 knots). Bottom contact observations were obtained from the height sensor, and on board Eldjarn this information was used to determine the beginning of each haul.

\section{Statistical methods and calculation}

The influence of depth on WS of the trawl is likely to be proportional to depth or linear on log scale. The results were studied by a multiple regression model:

$$
\hat{Y}_{i}=a+b_{1} X_{1 i}+b_{2} X_{2 i}+b_{3} X_{3 i}
$$

where $\hat{Y}$ is $\log$ of WS, $X_{1}$ is log of depth and $X_{2}$ and $X_{3}$ are "dummy variables" for ship effect and area effect respectively and $a$ and $b$ are constants (Zar, 1974).

Comparison of indices of abundance was done using two models. The standard indices (I) were calculated according to Model I: Constant Swept Area Model

$$
I=\bar{X}_{s t} * A * 10^{-6} / S A
$$

where $\bar{X}_{s t}$ is the stratified mean catch (numbers) in a stratum with area $A$. The standard swept area (SA) is 0.0405 naut. miles ${ }^{2}$ based on a standard haul distance of 3 naut. miles at an effective path width of $25 \mathrm{~m}$ (Hylen et al., 1986).

A corrected abundance index $\left(I_{c o}\right)$ is obtained according to Model II: Varying Swept Area Model

$$
I_{c o}=\bar{X}_{\text {st }}{ }^{*} A * 10^{-6} / S A_{c o}
$$

where $S A_{c o}$ is the corrected swept area in a stratum with area $A$.

Combining (2) and (3) gives:

$$
\mathrm{I}_{\mathrm{co}}=1 * \mathrm{SA} / \mathrm{SA} \mathrm{A}_{\mathrm{co}}
$$

When using (4) to correct the standard indices for varying trawl geometry, it is assumed that swept area is linearly related to the WS and thus (4) can be transformed to:

$$
I_{c o}=1 * W S_{k} / W S
$$

where $W S_{k}$ is the constant wingspread related to the constant standard swept area used in Model I. To demonstrate the possible effect on the abundance indices of varying spread of the trawl, WS estimated from a regression model for average depth within each depth zone is used. This approach may be approximate due to the fact that WS was recorded in less than $40 \%$ of the standard hauls. The calculations were done under three options:

1. Standard swept area is valid in the shallowest depth zone $(0-100 \mathrm{~m})$. The $I_{\text {co }}$ values are thus the same as 1 in this depth zone, and in equation (5) this appears as $W S_{k}$ being equal to the estimated WS. In the 200-300 m depth zones the abundance indices are obtained from equation (5), i.e. the standard indices are modified by the relationship between estimated WS at $0-100 \mathrm{~m}$ and $200-300 \mathrm{~m}$. The same procedure is repeated for the $300-400 \mathrm{~m}$ and 400-600 $\mathrm{m}$ depth zones.

2. Standard swept area is valid in the deepest depth zone $(400-600 \mathrm{~m})$. Here $W S_{k}$ equals the estimated $W S$, and hence $I$ and $I_{c o}$ indices are the same in this depth zone. In the other depth zones standard indices are modified by equation (5), i.e. keeping $W S_{k}$ constant and varying WS with depth

3. Standard swept area is valid in depth zone 200-300 $\mathrm{m}$, which is most comparable to the depths in the Barents Sea cod survey. $I$ and $I_{\text {co }}$ indices are thus the same in this depth zone, and the procedures used under option 1 and 2 were followed to modify $I$ to $I_{\text {co }}$ indices for other depth zones.

\section{Results}

\section{Wingspread}

Wingspread measurements from the Eldjarn and Raiti varied from about $11 \mathrm{~m}$ at $50 \mathrm{~m}$ depth to about $19 \mathrm{~m}$ at depths beyond $400 \mathrm{~m}$ (Fig. 3). The data were scattered, particularly the data from Eldjarn, but a depthWS relationship was nevertheless indicated. To analyze this relationship more closely, log transformations were performed and linear regression lines computed (Fig. 4). The Raiti stations were from the western slope, while Eldjarn also measured gear geometry in the eastern part of the area. The linear regressions on the Eldjarn data indicated an area difference (Fig. 5).

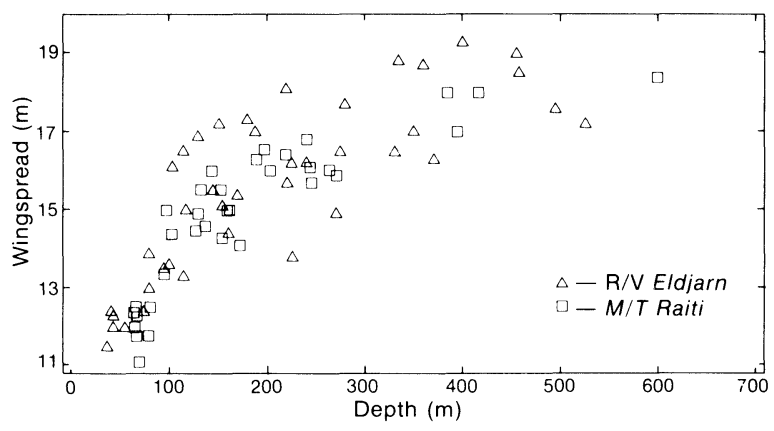

Fig. 3. Wingspread (WS) against depth for R/V Eldjarn and M/T Raiti. 


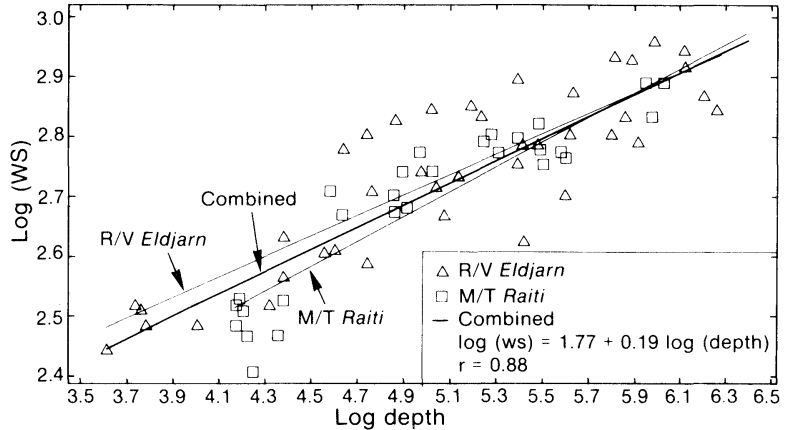

Fig. 4. The relationship between log transformed wingspread (WS) and depth measurements for R/V Eldjarn and M/T Raiti. Linear regression lines are shown for individual and combined data.

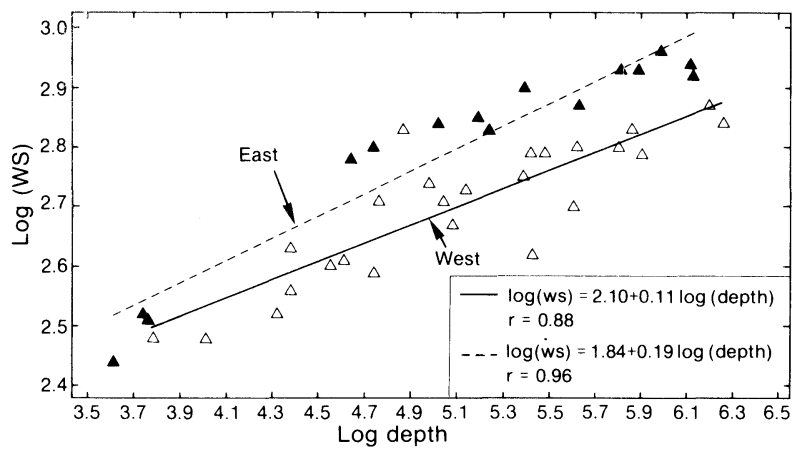

Fig. 5. Log transformed data for wingspread (WS) and depth from $\mathrm{R} / \mathrm{V}$ Eldjarn for eastern and western area. Linear regression lines are indicated.

In the regression analyses there was no significant ship-effect, while a significant area-effect was found (Table 2), indicating that differences in bottom condition from one area to another may add variability to WS measurements.

\section{Towed distance}

Several hauls on the Eldjarn showed considerable disagreement between the time of first bottom contact as recorded by the SCANMAR height sensor and as determined in the conventional way by the officer on watch. In deep water the discrepancy was as much as $10 \mathrm{~min}$. Normally this would lead to a too-early start of the haul, and the bottom area swept by the trawl was consequently overestimated proportionately. The same problem was not experienced on the Raiti, which used the heavier Vee-doors. On the Eldjarn the beginning of the haul was determined on the basis of height sensor readings when available.

\section{Geometry of trawl opening and quality of haul}

There was a significant correlation in the measurements of TH and WS (Fig. 6). In some cases instrument readings were in disagreement with this relationship
TABLE 2. Results from the regression analysis using log of wingspread as the dependent variable and depth as the independent variable.

\begin{tabular}{|c|c|c|c|c|}
\hline & Coefficient & $\begin{array}{c}\text { Standard } \\
\text { error }\end{array}$ & t-value & $\begin{array}{c}\text { Significance } \\
\text { level }\end{array}$ \\
\hline \multicolumn{4}{|c|}{ Ship and area included as "Dummy variables" } & $\mathrm{R}_{\mathrm{a}}^{2}=0.843$ \\
\hline Constant & 1.870 & 0.054 & 34.75 & 0.000 \\
\hline Depth & 0.183 & 0.010 & 18.46 & 0.000 \\
\hline Area & -0.100 & 0.018 & -5.49 & 0.000 \\
\hline Ship & -0.009 & 0.015 & -0.63 & 0.529 \\
\hline \multicolumn{4}{|c|}{ Ship included as "Dummy variable" } & $\mathrm{R}_{\mathrm{a}}^{2}=0.844$ \\
\hline Constant & 1.870 & 0.054 & 34.75 & 0.000 \\
\hline Depth & 0.183 & 0.010 & 18.46 & 0.000 \\
\hline Area & -0.100 & 0.018 & -5.49 & 0.000 \\
\hline \multicolumn{4}{|c|}{ No "Dummy variable" } & $\mathrm{R}_{\mathrm{a}}^{2}=0.771$ \\
\hline Constant & 1.772 & 0.061 & 29.11 & 0.000 \\
\hline Depth & 0.186 & 0.012 & 15.59 & 0.000 \\
\hline
\end{tabular}

for a considerable period of time (more than $1 \mathrm{~min}$.). This indicated either bad bottom contact or a fallen door (as determined by scratches and mud deposits on the doors after haulback). Examples of such cases shown in Fig. 6 were not included in the regression. Problems of this nature were observed on several occasions on the Eldjarn and were corrected during the haul. No such problems were observed on the Raiti.

Trawl geometry changed notably with depth as demonstrated by the schematic diagram in Fig. 7 of the trawl opening at $50 \mathrm{~m}$ and $450 \mathrm{~m}$. If it is assumed that the trawl opening is elliptical as indicated, it covers an area of $57 \mathrm{~m}^{2}$ in both cases, however, only about $70 \%$ of the area covered coincides (double hatched area in Fig. 7).

\section{Abundance indices}

In Table 3, standard abundance indices derived from Model I, Constant Swept Area Model (from God $\varnothing$ and Nedreaas, 1986) are compared with recalculated abundance indices using Model II, Varying Swept Area Model (Table 3B). When SA is assumed to be valid in the depth interval $0-100 \mathrm{~m}$, the corrected total index is $9 \%$ lower than the standard index. Here the reduction is most prominent for fish older than age 4 . When SA is assumed valid in 200-300 $\mathrm{m}$ and $400-600 \mathrm{~m}$ depth intervals, the total index is increased by 23 and $37 \%$ respectively. In contrast to the results under the first option, here the estimates of younger fish more than the older are influenced.

\section{Discussion}

Engås and God $\varnothing$ (1986) found that the two sets of doors used in the present studies resulted in similar trawl geometry, and the WS measurements here con- 


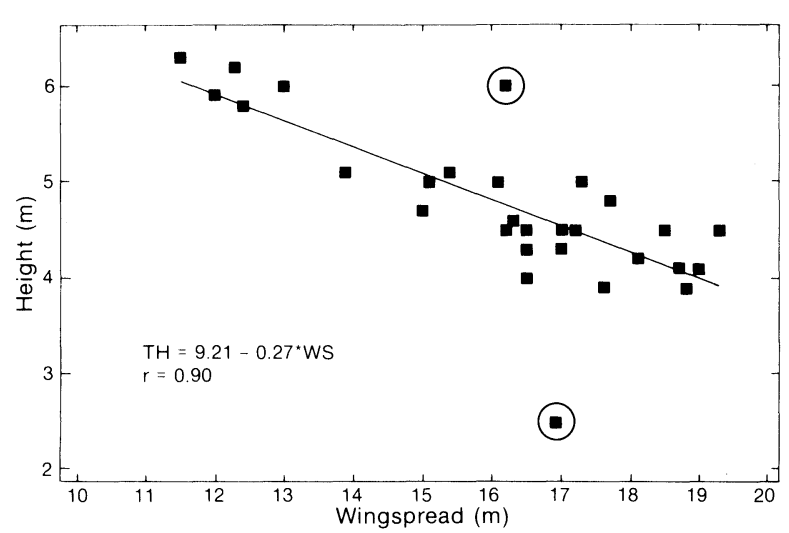

Fig. 6. Trawl height (TH) and wingspread (WS) measurement relationship shown with a linear regression line. Encircled points were not included in regression.

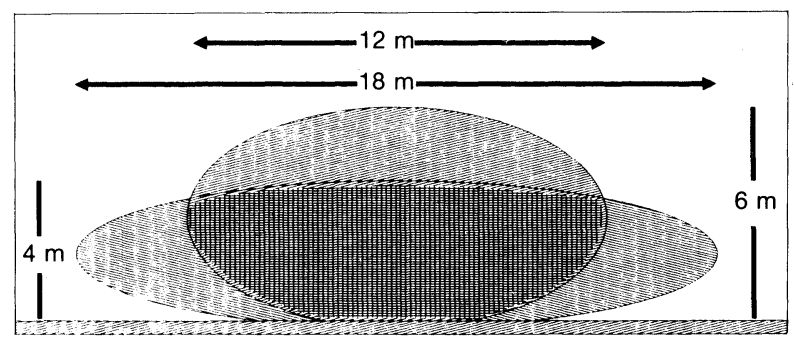

Fig. 7. Schematic representation of trawl opening at depths of 50 $\mathrm{m}$ and $450 \mathrm{~m}$.

firm this. The results also showed that operational problems like instability on bottom, were greater with the Waco doors. This implies difficulties in estimating exact time of proper bottom contact and may affect the assumed area swept by a haul, and hence increase variability in the calculated indices of abundance. High variability of abundance estimates is a serious concern in bottom trawl surveys (Carrothers, 1981; Byrne et al., 1981). Even though the effect of using instruments to evaluate haul quality and to determine the exact time of first bottom contact was not estimated, it was indicated that such procedures may help decrease variability in bottom trawl survey indices.

A considerable part of WS variability, and thus variation in swept area, was as expected found to be associated with variation in depth (Table 2 ). The significant area factor in the regression model was probably linked to an east-west difference in bottom and/or current conditions. Such differences have been thought be be among the major factors responsible for between tows variability (Carrothers, 1981). Survey experience has revealed differences in these factors between the western continental slope and in the eastern area. Particularly soft bottom conditions giving higher spreading forces to the doors, are believed to be responsbile for the generally wider WS in the eastern area (unpublished data). Variability in the trawl instru-
TABLE 3. (A) Standard abundance indices derived from Modell, and (B) recalculated abundance indices with Model II using reference depth zones $0-100 \mathrm{~m}, 200-300 \mathrm{~m}$ and $400-$ $600 \mathrm{~m}$. (The wingspread used in the Model II are obtained from the regression equation in Fig. 4. Div (\%) is deviation from standard indices.)

\begin{tabular}{lrrrrrrrr}
\hline \hline \multicolumn{7}{c}{ (A) Model I: Standard Indices } \\
Depth & 1 & 2 & 3 & 4 & 5 & 6 & $>7$ & Total \\
\cline { 2 - 8 } & \multicolumn{7}{c}{ Age } \\
\hline $0-100$ & 12.9 & 79.9 & 54.9 & 14.1 & 1.8 & 0.8 & 0.1 & 164.5 \\
$100-200$ & 10.4 & 31.3 & 12.8 & 6.5 & 1.5 & 1.5 & 0.5 & 64.5 \\
$200-300$ & 3.4 & 17.6 & 4.0 & 3.3 & 1.3 & 1.9 & 0.5 & 32.0 \\
$300-400$ & 0.3 & 2.3 & 1.6 & 2.6 & 1.2 & 1.9 & 0.5 & 10.4 \\
$>400$ & 0.1 & 1.0 & 1.0 & 1.5 & 0.8 & 1.5 & 0.4 & 6.3 \\
\hline Total & 27.1 & 132.1 & 74.3 & 28.0 & 6.6 & 7.6 & 2.0 & 277.7 \\
\end{tabular}

(B) Model II: Corrected Indices

Reference depth zone 0-100 $\mathrm{mWS}_{\mathrm{k}}=12.2 \mathrm{~m}$

\begin{tabular}{lrrrrrrrr}
\hline $0-100$ & 12.9 & 79.9 & 54.9 & 14.1 & 1.8 & 0.8 & 0.1 & 164.5 \\
$100-200$ & 8.5 & 25.5 & 10.4 & 5.3 & 1.2 & 1.2 & 0.4 & 52.5 \\
$200-300$ & 2.5 & 13.0 & 3.0 & 2.4 & 1.0 & 1.4 & 0.4 & 23.7 \\
$300-400$ & 0.2 & 1.6 & 1.1 & 1.8 & 0.8 & 1.3 & 0.3 & 7.3 \\
$>400$ & 0.1 & 0.7 & 0.7 & 1.0 & 0.5 & 1.0 & 0.3 & 4.2 \\
\hline Total & 24.2 & 120.7 & 70.0 & 24.6 & 5.3 & 5.7 & 1.5 & 252.0 \\
Div. (\%) & -11 & -9 & -6 & -12 & -19 & -24 & -25 & -9
\end{tabular}

\begin{tabular}{lllllllll} 
Div. (\%) & -11 & -9 & -6 & -12 & -19 & -24 & -25 & -9 \\
\hline
\end{tabular}

Reference depth zone 200-300 $\mathrm{m} \mathrm{WS}_{\mathrm{k}}=16.5 \mathrm{~m}$

\begin{tabular}{lrrrrrrrr}
\hline $0-100$ & 17.4 & 108.1 & 74.3 & 19.1 & 2.4 & 1.1 & 0.1 & 222.5 \\
$100-200$ & 11.4 & 34.4 & 14.1 & 7.2 & 1.7 & 1.7 & 0.6 & 71.0 \\
$200-300$ & 3.4 & 17.6 & 4.0 & 3.3 & 1.3 & 1.9 & 0.5 & 32.0 \\
$300-400$ & 0.3 & 2.2 & 1.5 & 2.5 & 1.1 & 1.8 & 0.5 & 9.8 \\
$>400$ & 0.1 & 0.9 & 0.9 & 1.3 & 0.7 & 1.3 & 0.4 & 5.6 \\
\hline Total & 32.7 & 163.2 & 94.7 & 33.3 & 7.2 & 7.8 & 2.0 & 340.9 \\
Div. (\%) & 21 & 24 & 28 & 19 & 10 & 2 & 1 & 23
\end{tabular}

Reference depth zone 400-600 $\mathrm{m} \mathrm{WS}_{\mathrm{k}}=18.4 \mathrm{~m}$

\begin{tabular}{lrrrrrrrr}
\hline $0-100$ & 19.5 & 120.5 & 82.8 & 21.3 & 2.7 & 1.2 & 0.2 & 248.1 \\
$100-200$ & 12.8 & 38.4 & 15.7 & 8.0 & 1.8 & 1.8 & 0.6 & 79.1 \\
$200-300$ & 3.8 & 19.6 & 4.5 & 3.7 & 1.4 & 2.1 & 0.6 & 35.7 \\
$300-400$ & 0.3 & 2.4 & 1.7 & 2.7 & 1.3 & 2.0 & 0.5 & 10.9 \\
$>400$ & 0.1 & 1.0 & 1.0 & 1.5 & 0.8 & 1.5 & 0.4 & 6.3 \\
\hline Total & 36.4 & 181.9 & 105.6 & 37.2 & 8.1 & 8.7 & 2.2 & 380.1 \\
Div. (\%) & 34 & 38 & 42 & 33 & 22 & 14 & 12 & 37 \\
\hline
\end{tabular}

mentation readings might also be a source of betweenhaul variation. The WS differences may partly be overcome by shooting extra warp length in the shallow areas. Direct observations of trawl geometry during all tows seem to be crucial for controlling the swept area in bottom trawl surveys.

The results show a close relationship between $\mathrm{TH}$ and WS. Due to the longer warps used in deep water, the fraction of the spreading force of the doors utilized to extend the trawl, increases with depth. As trawls are flexible structures of limited size, increased horizontal stretch will lead to decrease trawl height as was observed. The large difference in trawl opening at different depths, probably affects the catching efficiency 
on target species; the extent is presently unknown. As comparability of data from different depths is essential for the survey results, attempts to maintain constant swept area throughout the survey is necessary. Using different sweep wire lengths at different depths, is not a satisfactory solution (Hagstrøm, MS 1987). The use of remote controlled spreading force on doors or a wire between warps which maintains constant doorspread at any depth are possibilities which could be explored in order to alleviate the problem.

The Svalbard area is characterized by large variations in depth, and the main target species are distributed from the shallowest banks to the deepest areas of the continental slope (God $\varnothing$ and Nedreaas, MS 1986). Further, most of the commercially exploited species have a size (age) dependent depth distribution. Comparison of the indices of abundance calculated using the two swept area models, shows that variation in swept area has not only a considerable effect on total estimated abundance of cod but also a significant effect on the estimated age distribution.

Calculations of abundance indices in the Barents Sea survey are also done with Model I. The Barents Sea survey area is relatively flat with depths mainly between $200 \mathrm{~m}$ and $300 \mathrm{~m}$ (Jacobsen, MS 1986), and the bias introduced by variability in swept area is consequently limited compared to the Svalbard survey. As total survey abundance of Northeast Arctic cod is derived by combining the two survey estimates, an error is introduced if swept area variation is not corrected for in the Svalbard survey. Improved comparability between the two surveys could be obtained by using Model II with standard swept area considered valid in depth zone 200-300 m. In this case the total Svalbard index is $23 \%$ higher than the standard. However, it must be stressed that there are several other factors confounding the comparison of Svalbard and Barents Sea estimates. For example, coverage during different periods of the year and the use of different lengths of sweep wires (Hylen et al., 1986).

The importance of monitoring trawl behaviour in surveys is widely discussed (Carrothers, 1981). In the early-1980s instrumentation for constant in situ monitoring of trawl geometry and performance during a whole groundfish survey was not available. Presently such instruments are available, and the results presented here clearly demonstrate the necessity and possibility of a better control of the trawl geometry and performance in groundfish surveys. However, if catching efficiency of the trawl changes when geometry varies considerably, the validity of correcting for swept area variability as done by Model II might be questioned.

\section{References}

BYRNE, C. J., T. R. AZAROVITZ, and M. P. SISSENWINE, 1981. Factors affecting variability of research vessel trawl geometry. In: Bottom trawl surveys, W. G. Doubleday and D. Rivard (eds.). Can. Spec. Publ. Fish. Aquat. Sci., 58: 258-272.

CARROTHERS, P. J. G. 1981. Catch variability due to variations in groundfish otter trawl behavior and possibilities to reduce it through instrumented fishing gear studies and improved fishing procedures. In: Bottom trawl surveys, W. G. Doubleday and D. Rivard (eds.). Can. Spec. Publ. Fish. Aquat. Sci., 58: 247-257.

ENGÅS, A., and O. R. GOD $\varnothing, 1986$. Influence of trawl geometry and vertical distribution of fish on sampling with bottom trawl. J. Northw. Atl. Fish. Sci., 7: 35-42.

FOREST, A., and J. P. MINET, 1981. Abundance estimates of the trawlable resources around the Island of St. Pierre and Miquelon (NAFO Subdiv. 3Ps): Methods used during the French research surveys and discussion of some results. In: Bottom trawl surveys, W. G. Doubleday and D. Rivard (eds.). Can Spec. Publ. Fish. Aquat. Sci., 58: 68-81.

GOD $\emptyset$, O. R., and K. NEDREAAS. MS 1986. Preliminary report of the Norwegian groundfish survey at Bear Island and West-Spitzbergen in the autumn 1985. ICES C.M. Doc., No. G:81, 22 p.

HAGSTR $\varnothing M, O$. MS 1987. Measurements of doorspread and headline height of the GOV trawl during IYFS 1987. ICES C.M. Doc., No. B:15, 10 p.

HALLIDAY, K. 1986. Bottom trawl survey methods in the eastern Bering Sea. In: A workshop on comparative biology, assessment, and management of gadoids from the North Pacific and Atlantic Oceans, M. Alton (ed.). Seattle, Washington, June 1985, p. 459-472.

HYLEN, A., and O. NAKKEN. MS 1985. Stock size of Northeast Arctic cod, estimates from survey data 1985/86. ICES C.M. Doc., No. G:67, 14 p.

HYLEN, A., O. NAKKEN, and K. SUNNANÅ. 1986. The use of acoustic and bottom trawl surveys in the assessment of North-east Arctic cod and haddock stocks. In: A Workshop on comparative biology, assessment, and management of gadoids from the North Pacific and Atlantic Oceans, M. Alton (ed.). Seattle Washington, June 1985, p. 473-498.

HYLEN, A., J. A. JACOBSEN, T. JAKOBSEN, S. MEHL, K. NEDREAAS, and K. SUNNANÅ. MS 1988a. Estimates of stock size of northeast Artic cod and haddock, Sebastes mentella and Sebastes marinus from survey data, winter 1988. ICES C.M. Doc., No. G:43, 29 p.

HYLEN, A., J. A. JACOBSEN, S. MEHL, and K. NEDREAAS. MS 1988b. Estimates of stock size of cod, haddock, redfish and Greenland halibut in the Barents Sea and the Svalbard area autumn 1987. ICES C.M. Doc., No. G:44, $25 \mathrm{p}$.

JACOBSEN, J. A. MS 1986. Bunntrålfangster: Representativiteten av tetthets-, arts- og lengdefordelinger for torsk og hyse i Barentshavet. University of Bergen (thesis).

JONSSON, E., O. K. PALSSON, S. A. SCHOPKA, B. AE. STEINARSSON, and G. THORSTEINSSON. MS 1986. Icelandic Groundfish Survey 1986. ICES C.M. Doc., No. G:73, $38 \mathrm{p}$.

WILEMAN, D. A. 1984. Model testing of the 36/47 m G.O.V. 
Young fish sampling trawl. Danish Institute of Fisheries Technology, Hirtshals. 43 p.
ZAR, J. H. 1974. Biostatistical analysis. Prentice-Hall, Inc., London, $620 \mathrm{p}$. 
